\title{
Implementation of Factories Act, 1948 in Haryana - A Comparative Study of Three Industries
}

\author{
Ashok Kumar Sheoran \\ (Research Scholar, Department of Commerce, NIMS University, Rajasthan)
}

\begin{abstract}
The First Factories Act was passed in 1881 for those industries, which employed 100 or more workers. Amendments to this Act were made in 1890, making it applicable to the undertakings having 50 or more workers as per the recommendations of the Bombay Factories Commission, 1890. After independence legislations like the Employees State Insurance Act, 1948; the Factories Act, 1948; Minimum Wages Act, 1948; Industries Act, 1951; the Employees Provident Fund, Family Pension Fund and Deposit Linked Insurance Fund Act, 1952; Maternity Benefit Act, 1961; the Payment of Bonus Act, 1965; the Payment of Gratuity Act, 1972 etc. were passed. However, the Factories Act, 1948 is considered more important because it incorporates safety, health and welfare measures for workers. The universe of the study consists of three industrial undertakings namely National Fertilizers Ltd., Panipat, SPL Ltd., Bahadurgarh and Cooperative Sugar Mill, Karnal in Haryana.
\end{abstract}

Keywords: Labour, Factories Act, National Fertilizers Limited (NFL), Somany Pilkington's Limited (SPL), Karnal Sugar Mills Limited(SM)

\section{Introduction}

Labour legislation in India is a development of post-independence period though its origin can be traced back to the industrial revolution. Having felt the need of enactment of labour laws to evolve a system for their welfare, the First Factories Act was passed in 1881 for those industries, which employed 100 or more workers. Amendments to this Act were made in 1890, making it applicable to the undertakings having 50 or more workers as per the recommendations of the Bombay Factories Commission, 1890. In the year 1901 Mines Act was enacted to improve the working conditions of mineworkers. In 1907, the Factories Labour Commission was constituted by the Government of India to study the working conditions of labour in industries. In pursuance of the recommendations of this Commission, the Factories Act, 1911 was passed for seasonal factories. The outbreak of the First World War in 1914 and the success of Russian Revolution led to a number of new developments and had a tremendous impact on the attitude of the government and the society towards labour ${ }^{[1]}$, which further led to the establishment of 'International Labour Organisation' in 1919, declaring that "labour is not a commodity" and that its management should be based on the principle of human and social justice. This infusing of human aspect in labour management by the I.L.O greatly influenced the enactments of labour legislations in India and many other developing countries.

The establishment of All India Trade Union Congress in 1920 also affected the governmental labour policy. Due to industrial unrest in 1919-1920, the Government of India passed the Factories Act, 1922, applicable to all factories using power and employing not less than 20 persons. It provided for 60 working hours in a week as well as that women and children may not be employed during 7.00 p.m. to 5.30 a.m. ${ }^{[2]}$

In 1923, the Mines Act was amended. This act prohibited employment of women in coalmines at the hazardous points. According to Workmen's Compensation Act, 1923 compensation for partial or total disablement or death during the course of employment could be claimed. ${ }^{[3}$ In 1929, Royal Commission on Labour was appointed which submitted its report in 1931. and observed that the working class of India was neither sufficiently organized nor properly stabilized. Unsafe and poor working conditions, problem of indebtedness, strikes and lockouts, migratory character of labour, strained industrial relations etc. were common problems faced by the industrial establishments at that time. The Commission recommended that a wage board should be constituted, workers committee be established, maximum working hours not to be more than 54 per week, maternity benefit legislation be passed, permanent statutory machinery for the settlement of industrial disputes be established for the welfare of labour class. ${ }^{[4]}$

These recommendations were made in the light of evils in the wake of industrial revolution of the $18^{\text {th }}$ Century. However, no concrete efforts were undertaken by the Government to implement these recommendations. In view of the recommendations made in this report, the Factories Act was amended in 1934 for providing facilities of drinking water, washing, rest intervals, medical treatment etc. in factories employing more than 150 workers. ${ }^{[5]}$ In 1944 , the grand charter of labour, popularly known as the 
Declaration of Philadelphia, was adopted in which the objectives of the ILO were revised and which strongly favoured the enactment of labour legislation in India. ${ }^{[6]}$

As a result, Labour Investigation Committee was appointed in 1944 to look into the problems of the workers like minimum wages, employment, housing, employment risks, working conditions etc. The Committee in its Report, 1946 suggested that a code of safety to avoid accidents, state insurance for employment injuries and occupational diseases, maternity benefit legislation, standardization of wages, recognition of trade unions, better housing conditions etc. should be ensured. ${ }^{[7]}$

After independence, provisions of fundamental rights and directive principles of state policy were made in Indian Constitution to boost the cause of the weaker sections including the labour. ${ }^{[8]}$ Moreover, legislations like the Employees State Insurance Act, 1948; the Factories Act, 1948; Minimum Wages Act, 1948; Industries Act, 1951; the Employees Provident Fund, Family Pension Fund and Deposit Linked Insurance Fund Act, 1952; Maternity Benefit Act, 1961; the Payment of Bonus Act, 1965; the Payment of Gratuity Act, 1972 etc. were passed. ${ }^{[9]}$ However, the Factories Act, 1948 is considered more important because it incorporates safety, health and welfare measures for workers. The universe of the study consists of three industrial undertakings namely National Fertilizers Ltd., Panipat, SPL Ltd., Bahadurgarh and Cooperative Sugar Mill, Karnal in Haryana.

\subsection{National Fertilizers Limited (NFL)}

\section{Profile Of The Universe}

National fertilizers limited (NFL) is an instrument of society. It has to serve the needs of people within the scope of its basic objectives. In terms of Memorandum of Association, NFL was set up to manufacture and market chemical fertilizers, other chemicals and by-products as well as to provide allied services.

NFL is a multi unit, multi product Company and is one of the India's largest producers of Nitrogenous fertilizers with a market share of $15 \%$. NFL is a Mini Ratna Company and has the distinction of being a profitable Public Sector Undertaking. It is incorporated in 1974 with two fertilizer plants at Bathinda (Punjab) and Panipat (Haryana), Nangal plant was merged with it in 1978 on the recognition from FCI and later NFL executed its gas based plant at Vijaipur (MP) and subsequently in 1997 doubled the capacity of Vijaipur. NFL's two popular brands are Kisan Urea and Kisan Khad. An ISO-9001: 2008 company, it is the first one to have ISO 14001: 2004 and OHSAS 18001: 2007 certification in India. ${ }^{[10]}$ Panipat Unit of NFL is situated on National Highway No. 1 on Delhi- Amritsar railway trunk route about $90 \mathrm{kms}$ from Delhi in the historical city of Panipat. The unit went to commercial production from 1.9.1979. The various plants and their capacities are as below:

TABLE 2.2

\begin{tabular}{|c|c|}
\hline Ammonia Plant & $900 \mathrm{MT} /$ day \\
\hline Urea Plant & $1550 \mathrm{MT} / \mathrm{day}$ \\
\hline Sulphur Recovery Plant & $26.5 \mathrm{MT} / \mathrm{day}$ \\
\hline Argon Recovery Plant & $120 \mathrm{NM}^{3} / \mathrm{hr}$ \\
\hline Steam Generation Plant & $3 \times 150 \mathrm{MT} / \mathrm{day}$ \\
\hline Captive Power Plant & $2 \times 15 \mathrm{MWH}$ \\
\hline Coal Handling Plant & $150 \& 250 \mathrm{MT} / \mathrm{Hr}$ \\
\hline DM Water Plant & $400 \mathrm{M}^{3} / \mathrm{Hr}$ \\
\hline Raw Water Plant & $2400 \mathrm{M}^{3} / \mathrm{Hr}$ \\
\hline Bagging Plant & $4000 \mathrm{MT} / \mathrm{day}$ \\
\hline Effluent Treatment Plant & $200^{3} / \mathrm{Hr}$ \\
\hline
\end{tabular}

\subsection{Somany Pilkington's Limited (SPL)}

The ceramic tiles industry is dependent on the growth in the construction industry and the housing sector. The government is offering incentives to bridge the demand supply gap of 40 million dwelling units. The tile is a low priced, attractive and easy to use product with a bright future. India's installing capacity for floor and wall tiles is around 130 million square meters per year. Production growth is largely centered in the west and sough where there is paucity of natural minerals. Utility of floor tiles in India has created a huge demand for floor tiles market, which has grown by $20 \%$ over the last few years leading to drop in the selling prices providing opportunities to consumers in this market.

Somany Pilkington's Ltd. (SPL) is one of the oldest and the largest companies in India engaged in the manufacturing of the ceramic tiles. The company diversified into the manufacture of the value-added vitrified tiles in 1999-2000 and also put up a floor tiles plant at Kadi (Gujarat) during 2000-2001. Kassar plant produces floor-tiles, wall tiles and vitrified tiles. The Kadi plant produces floor tiles and wall tiles, both plants are ISO certified, additionally, the Kadi Plant has an ISO 14001 certification, the first instance of this in the ceramic tile industry in the world. SPL enjoys a basket of approximately 600 designs and 1200 colour combinations. The 
company's aggregated capacity is 36,000 sq.m per day at Kassar. The material is largely sold within India. SPL exports to Dubai, Doha, Fiji, Bahrain, Brussels, Kuwait, Ghana, Maldives, Mauritius, Mozambique, New Zealand, Audi Arabia South Africa, Uganda, West Indies, Yemen, Zambia and other countries in the region. ${ }^{[11]}$

\subsection{Karnal Sugar Mills Limited}

Co-operative movement has been acknowledging being a very important, effective and powerful medium of economic development for the society. It has three -fold objective of alleviating poverty, generating gainful employment opportunities and eliminating economic backwardness in different sectors like institutional debt, housing, labour and production, handlooms, industries, urban finance, milk and other processing sectors. The Karnal Sugar Mill was registered on March 3, 1966 under Punjab Co-operative Societies Act, 1961 and it was issued a license for crusing capacity of 1250 TCD. It is situated on Meerut Road in Karnal. It became operative w.e.f January 1, 1977 with the investment of 6.64 crores. It is providing employment to about 2000 employees. Export quality of sugar is being produced by the Mill which is of the best quality in Northern India which has been testified by Pepsi Laboratories, an international company.Interest free cane seed loan for high sugared varieties is given and subsidy is provided for seed and soil treatment. To encourage the farmers for increasing cane production, the outstanding farmers are being honoured at the Mill's level by distributing cash prizes. Various facilities being provided to cane growers include cash incentives for growing cane seed nurseries, supply of improve cane varieties, subsidy on transport, supply of chemicals insecticides and pesticides at subsidized rates, supply of sugar at subsidized rates to growers linked with supply of cane to the mills etc. In addition, one bag of DAP and urea is also supplied to the cane growers free of cost for high sugared varieties. ${ }^{[12]}$

\section{Objectives Of The Study}

The main objectives of the study are:

I. To know about the awareness of workers about the Factories Act, 1948.

II. To evaluate the adequacy of various provisions of the Act.

III. To examine the implementation of the Act.

IV. To study the effectiveness of administrative machinery in implementing the Act.

\section{Hypotheses}

1. Labour is less aware of various provisions of the Act because of the lack of education, their migratory character, poverty, rural background, nature of the industry etc.

2. Implementation of the Act is not much effective.

3. Administrative machinery and the staff for implementing the Act are inadequate.

4. Trade Unions have little role in the effective implementation of the Act.

\section{Methodology}

This study intends to examine the implementation of the Factories Act, 1948 in the universe of its study. For this purpose, the relevant information has been collected from primary sources and supplemented by secondary sources wherever necessary. Interview schedules have been worked out to elicit factual information from the workers, trade unions, management and the district inspectorates a Purposive sample of 50 workers, five respondents of management, five representatives of trade union of each undertaking and a total of five representatives of inspectorate staff has been drawn. Informal dialogues have been held to ascertain the reliability of information so gathered. However, the study confines itself strictly to the three units only.

\section{Application Of Chi-Square}

Chi-Square, a research tool to verify the inter-dependence of different variables, is applied to examine the worker's their awareness about the Factories Act, 1948 and their response regarding actual implementation of various provisions of the Act. It is assumed in the hypothesis that such aspects differ significantly from one industry to another. If Chi-Square calculated is greater than Chi-Square tabulated, it supports and verifies the hypothesis that the worker's awareness about the Act and its implementation vary from industry whereas the vice-versa confirms the homogeneity of views of the workers in all the three industries.

\section{Result Of The Study}

\subsection{Awareness of workers about health provisions in the factories act, 1948}

- On an average, $73 \%$ workers are aware of provisions related to cleanliness. The level of awareness is highest in NFL and the lowest in SPL. 
- $\quad 88.6 \%$ workers are aware of provisions of waste and effluents, lighting and drinking water. However, their number is the highest in NFL and the lowest in SPL.

- $61.3 \%$ workers are aware of ventilation and certain degree of temperature of be maintained again, the highest awareness is in case of NFL and the lowest in SPL.

- $70 \%$ are aware of restriction on overcrowding and cleanliness of latrines and urinals. The highest number of aware workers is in NFL and the lowest in SPL.

\subsection{Awareness of safety provisions}

- In all the three sampled units $70 \%$ workers are aware of the provisions related to fencing, $66.07 \%$ workers are aware of the precaution to be taken while working on machinery in motion, self- acting machines, lifts, hoists etc. and NFL showing the best implementation

- $40 \%$ workers are aware of the maintenance of floors, stairs and means of access. However, NFL has the largest number of satisfied workers.

- $\quad 86.7 \%$ workers are aware of the protection provided in case of eyes where as $76.07 \%$ are satisfied with the protection from explosive/ inflammables gas etc.

- $\quad$ Regarding fire control, $78.7 \%$ are aware of the precautionary measures.

- $80 \%$ workers in NFL and SM are aware of provisions of safety officer but there is no such officer in SPL.

- The level of awareness regarding health provisions is the highest in NFL (77\%) followed by SM (57\%) and the lowest in SPL i.e. (46\%).

\subsection{Awareness of the welfare provisions}

- Regarding washing facilities only $33.4 \%$ workers in the three units on an average are aware, their percentage being the highest in NFL and the lowest in SPL.

- Half of the Workers are aware of the facilities for drying and storing clothes, but it is highest in NFL and Lowest in SPL.

- As regards sitting facilities, $66.7 \%$ workers are aware, their number being the highest again in NFL and the lowest in SPL.

- $\quad 48.7 \%$ workers are aware of first aid appliances. The workers in NFL display the highest level of awareness where it is the lowest in case of SM.

- Regarding canteen facilities $68.7 \%$ workers are aware. However, it is the highest in NFL and the lowest in SM.

- $43.3 \%$ workers are aware of the facilities to be provided for shelter/ rest rooms with SM having the largest number of enlightened workers.

- Only $20 \%$ workers on an average are aware of provisions of labour welfare officer.

- On the whole the level of awareness of welfare provisions is the highest in NFL (53.3\%) followed by SM (39.5\%) and SPL (31.25\%) the workers are more aware of the facilities of canteen and sitting but they seem to be least bothered about provisions of labour welfare officer and washing.

\subsection{Implementation of health provisions}

- on an average, in the three units $66.7 \%$ workers are satisfied with the provisions of cleanliness, their number being the highest in NFL and the lowest in SPL, 73.3\% union leaders, on an average in the three units are happy with the implementation of these provisions where as $93.3 \%$ management personnel appreciate the efforts made in this direction. In NFL, chemical washing air, cleaning, water washing etc. all requirements to the work place takes place. But, in SM and SPL the premises do not give a healthy look.

- Regarding wastes and effluents $80 \%$ workers, $93.3 \%$ union leaders as well as managers commend the steps taken for its disposal and treatment.

- $63.3 \%$ workers responded that the arrangement made for proper ventilation and keeping suitable temperature is adequate. The workers in SPL complained of high temperature in summer season. But, 66.7 $\%$ union leaders and $93.3 \%$ managers also expressed their satisfaction and told that it is practically not feasible to keep the temperature under control due to nature to work. 
- $\quad 88 \%$ workers praise the restrictions imposed on overcrowding of the work room where as $93.3 \%$ of both union leaders and managers also felt good.

- $\quad 86 \%$ workers and union leaders in all the three units are happy with the lighting arrangement where as 93.3\% managers are also highly appreciative this provisions.

- Regarding water, $72 \%$ workers, $80 \%$ union leaders and $93.3 \%$ managers find the provisions adequate, although the workers in SPL are not happy with the quality and cooling of drinking water. The place around the water cooler is covered with algae and gives an unhygienic look to the surroundings.

- As far as latrines and urinals are concerned, $53.3 \%$ workers, $73.3 \%$ union leaders and $93.3 \%$ managers find them according to the specified norms. The workers in SM and SPL report that these are not cleaned properly and stink all the time.

- The workers in SM and SPL are highly critical of the non availability of spittoons whereas, in NFL, sufficient number of wash basins has been provided at suitable places, $93.3 \%$ union leaders and $60 \%$ managers find the arrangements adequate.

- In General, $72.8 \%$ workers in NFL, the highest of all the three units, are happy with the provisions made for promoting good health among the workers followed by SM 58.3\% and SPL 56.1\% The most appreciated provisions include lighting, disposal of wastes and effluents, overcrowding etc. Whereas non availability of spittoons, maintenance of urinals and toilets is highly criticized.

\subsection{Implementation of safety provisions}

- As far as fencing of the working machinery and working on its is concerned $80 \%$ workers, on an average, express satisfaction, $86.70 \%$ union leaders are also contented. However, in SM and SPL some cases of negligence regarding fencing of revolving machine parts have been pointed out. $82 \%$ workers and $93 \%$ union leaders accept the availability of self acting machines.

- $\quad 63.3 \%$ workers and $80 \%$ union leaders, on an average confirm availability of hoists. Lifts/ chains etc. But workers in SM complained of the problem of carrying excessive weight on back up to five floors, as there is no satisfactory provision of lifts.

- The welders in NFL have been provided with effective screens, gloves apron, face sheet, PVC suit, safety suit etc. Nevertheless, the workers in SM complain of the inadequacy of such facilities.

- $60 \%$ workers and $86.7 \%$ union leaders admire the precautions taken in case of explosive/ inflammable dust and gas etc.

- $\quad 65.7 \%$ workers and $93.3 \%$ leaders are happy with measure with fire control. Half of the workers and $60 \%$ union leaders on an average appreciate the working of the Safety Officer. Unfortunately, there is no safety officer in SM where as there are six such officers in NFL.

- Thus, highly satisfied workers are those of NFL $82.8 \%$ followed by SPL $68.6 \%$ and SM $45.6 \%$. They have positive views about provisions related to fencing the machinery, work on machinery in motion and self acting machines. But, they express grave concern over the absence of notices showing speed of revolving machines in SPL and SM. NFL has the distinction of possessing fully automatic plant where everything is regulated and monitored from the control room. Hence, there is no need of notices near machinery as any error in the speed is reflected on the monitors in the control room.

- Moreover, in NFL, safety of the workers is a prime concern as reflected by the existence of a full fledge safety Department equipped with latest and modern instrument with six safety officers. Workers are provided compulsory safety training when promoted to the next higher grade and also given safety helmets, ear plugs for noise, fresh air cylinders gas, masks etc. But SM and SPL are deficient in these provisions, even, there is no safety officer.

\subsection{Implementation of welfare provisions}

- Only 33\% workers, in the three units, on an average are satisfied with the washing facilities but $80 \%$ union leaders and all the managers claim workers arrangement made in this regard. However, the workers in NFL get kit maintenance allowance in lieu of this facility at a rate of $8 \%$ of the basic salary.

- As regards the facilities for drying and storing clothes, 50\% workers, $90 \%$ union leaders and $86.7 \%$ managers are contented. Again, the workers in SM complain of the lack of required number of cupboards of closets where as those in SPL do have any access to this provision. 
- $\quad$ Regarding first aid appliances, $50.7 \%$ workers, $66.7 \%$ union leaders and $93.3 \%$ managers are appreciative. There is one first aid box in each section in NFL with prescribed contents and a ready ambulance round the clock. Whereas the conditions of such boxes in SM and SPL is not so good. Moreover, the hospital in the NFL township is also providing good service where as in case of the other two concerns. The dispensaries are not properly maintained and open just for two to three hours a day. Even the medicines for common diseases are not available most of the times.

- $\quad 68.7 \%$ workers praise the facility and operation of canteen where as all union leaders and managers are happy with the functioning of the canteen. The workers in SM and SPL get the food items/ eatables at subsidized rates where as in NFL the items are provided at market rates and workers are given canteen allowance at the rate of $10 \%$ of the basic pay. Conditions of the canteen and furniture are also good here where as in SM and SPL food stuffs are prepared under unhygienic conditions. The floor, furniture and utensil are dirty here.

- As far as shelter/ rest rooms are concerned, $43.3 \%$ workers find the arrangement suitable. The retracing room in NFL has sufficient number of chairs and tables but there are no separate/ shelter rest room for workers in SM and SPL. There is a shelter room for farmers in SM but it is not well maintained and suitable furnished.

- As the number of female workers is less than thirty in all the three units, there is no provisions of crèche

- Only $20 \%$ workers, on an average, are happy with the working of the labour welfare officer where as 53.3\% union leaders and all the managers are satisfied.

- The workers are not satisfied with the working of the trade unions, $76.7 \%$ workers criticize their attitude towards the implementation of various provisions.

In a nutshell, it can be said that the level of awareness of workers is the highest $60 \%$ in case of safety provisions followed by provisions for good health $58 \%$ and the lowest in case of welfare provisions $41.35 \%$ It is seen that the highest number of aware workers are in NFL because they are better educated, paid and placed than others. As far as the implementation of these provisions is concerned, safety provisions are implemented with $65.5 \%$ success rate followed by health provisions $62.4 \%$ and welfare provisions $41.9 \%$. It means the implementation of various provisions is related to awareness of those provisions.

On the whole, the hypothesis "implementation of the Act is not much effective" is accepted. Next hypothesis, "Administrative machinery and the staff for implementing the Act are inadequate "is accepted. Similarly, the hypothesis, "Trade unions have little role in the effective implementation of the Act' is also accepted. The last hypothesis "the degree of its implementation varies in central, state and private establishment" is accepted.

\section{Suggestions}

- Local level workshops and seminars should be organized to supplement and update worker's knowledge about their rights in terms of various provisions of the Act.

- Local language communication is essential for generating awareness among workers.

- Manuals, handouts, pamphlets, etc. in comprehensible languages should be distributed to the workers at the time of their appointment and also from time to time.

- The workers should be invited to explain their problems, grievances and reservations of any kind without fear. A particular time should be fixed for this purpose and the redressal should be prompt and satisfactory.

- Trade unions should organize various programmes to aware the workers of their rights instead in just indulging themselves in petty politics for their vested interests.

- Premises in SM and SPL should be cleaned properly daily and disinfectants should be used weekly.

- Sufficient number of exhaust fans should be installed in SPL to provide relief from the workers of high temperature during summer reason. Urgent steps should be taken to improve the quality and cooling of drinking water, the area around taps and water cooler should be cleaned properly to prevent diseases from spreading out.

- In SM and SPL, maintenance and the cleaning of latrines and urinals and spittoons needs immediate attention to prevent dangerous diseases.

- The unfenced revolving parts of the machinery must be fenced out on priority basis to avoid accidents. 
- The workers in SM need respite from the problem of carrying excessive weight. Either proper arrangement of lifts should be made or the size of the carrying bags be reduced to $50 \mathrm{~kg}$ in compliance with the directions of world Human Rights Commission.

- The welders in SM should also be provided with various safety equipments like gloves, apron, face sheets, safety suits etc.

- Required number of safety officers should be appointed in SPL and SM as safety of the workers.

- Washing, drying and storing facilities for clothes according to the provisions of factories Act, 1948 should be provided in the premises of SM and SPL.

- Prompt attention should be given for arranging first aid boxes, ambulance and maintaining the dispensaries according to the specifications in SM and SPL. The mismanagement of funds and exploitation of workers by ESI should also be curbed.

- Adequately furnished Shelter/rest room should be provided for the workers.

- The management is not serious about providing non statutory welfare provisions although some of them are directly related with the quality of workers life.

- The wages of the workers in SM and SPL should be revised in consonance with the other public sector undertakings and the wage Boards should be constituted on priority basis to review the wages time to time.

- Timings of the working shift in SM should be revised on the pattern of NFL and SPL to avoid the inconvenience of workers.

- Some sorts of provisions be inserted in the factories Act to regulate the daily wagers.

- District vigilance committees should be formed to keep an eye over corrupt officials and defaulters.

- The vacant post of Factory Inspectors should be filled regularly to make the inspection effective.

- Internal leadership in the trade unions should be strengthened to increase their bargaining power and to encourage the concept of participatory management.

To conclude, it can be suggested that the Government must consider the disparity in wages and working conditions in the concerns of workers.

\section{References}

[1] Balwant Singh; Labour Policy and Administration; Delhi: M.D. Publications; 1996; p. 16

[2] B.D. Rawat; Labour Welfare in India; Jaipur: RBSA Publichsers; 1988; pp 56-57.

[3] S.N. MIshra; Labour and Industrial Laws, Central Law Publications, 2009; pp 287-288.

[4] C.B. Mamoria; Labour Welfare, Social Security and Industrial Peace in India; volume II; Allahabad: Kitab Mahal; $1983 ;$ p.1.

[5] S.N. Mehrotra; Labour Problems in India; New Delhi: S. Chand; 1976; pp. 199-200.

[6] R.C.P. Singh; Labour Welfare Administration in India; New Delhi: Deep and Deep; 1989; pp 57-58.

[7] S.N. Mehrotra; Op. Cit; pp 199-200.

[8] Balwant Singh; Op. Cit; p. 17

[9] Statistical Abstract of Haryana; Economic and Statistical Organisation; Planning Department; Government of Haryana, Chandigarh: 2003, p. 385.

[10] Annual Report, NFL, 2011-12, p.1.

[12] Annual Report, SPL, 2011-12, p.1.

[13] Annual Report, SM, 2011-12, p.1. 